\title{
Overexpression of S100A4 as a biomarker of metastasis and recurrence in oral squamous cell
} carcinoma

\author{
Jayalakshmi NATARAJAN ${ }^{1}$, Keith HUNTER ${ }^{2}$, Vimi S MUTALIK ${ }^{3}$, Raghu RADHAKRISHNAN ${ }^{4}$ \\ 1- Department of Oral Pathology and Microbiology, Manipal College of Dental Sciences, Manipal University, Manipal, India. \\ 2- Department of Oral and Maxillofacial Pathology, University of Sheffield, Sheffield, UK. \\ 3- International Medical University, Kuala Lumpur, Malaysia. \\ 4- Department of Oral Pathology and Microbiology, Manipal College of Dental Sciences, Manipal University, Manipal, India; Marie Curie Fellow, University of \\ Sheffield, Sheffield, UK.
}

Corresponding address: Raghu Radhakrishnan - Marie Curie International Incoming Fellow - E13, Dept. of Oral Pathology, School of Clinical Dentistry University of Sheffield, Sheffield - S102TA - United Kingdom - Phone - 00447597096009 - e-mail: r.a.radhakrishnan@sheffield.ac.uk raghu.radhakrishnan@ gmail.com

Submitted: April 10, 2014 - Modification: June 11, 2014 - Accepted: June 18, 2014

\section{ABSTRACT}

S100A4, a biomarker of epithelial mesenchymal transition (EMT), plays an important role in invasion and metastasis by promoting cancer cell motility. In oral squamous cell carcinoma (OSCC), metastasis results in $90 \%$ of cancer associated mortality. Objective: To investigate the role of S100A4 expression as an important component of the epithelial mesenchymal transition (EMT) program in oral squamous cell carcinoma (OSCC). Material and Methods: S100A4 protein expression was assessed semi-quantitatively by immunohistochemistry in 47 histologically confirmed cases of oral squamous cell carcinoma (OSCC) and 10 normal oral mucosal biopsies. The association between the S100A4 overexpression and the aggressive features of OSCC were analyzed by X2 test. Results: Moderate to strong cytoplasmic expression of S100A4 was observed in 30 out of 47 specimens of OSCC (64\%). Overexpression of S100A4 was significantly associated with the clinical stage, lymph node involvement, metastases, pattern of invasion and recurrence $(p<0.05)$. Conclusion: S100A4 expression represents an important biomarker of prognostic significance that may be used to identify a subset of patients at high risk of invasion and metastasis.

Keywords: Biomarker. Epithelial-mesenchymal transition. Oral cancer. Metastasis. Prognosis.

\section{INTRODUCTION}

Initiation and early growth of primary epithelial cancers, and acquisition of invasiveness is thought to herald the advanced stages of this multistep process that eventually leads to metastatic dissemination, with life-threatening consequences ${ }^{11}$. The genetic control and biochemical mechanisms underlying the acquisition of the invasive phenotype are mediated by the activation of an epithelial mesenchymal transition (EMT) program ${ }^{13}$. EMT is a biologic process that allows an epithelial cell to acquire the properties of a mesenchymal cell, thereby promoting invasion into the surrounding stroma and intravasation of tumor cells ${ }^{27}$. A number of distinct molecular markers are engaged in order to initiate EMT and enable its completion. One such marker is the S100A4, a filament-associated calcium-binding protein, which is associated with the cells of mesenchymal origin, and deemed to play a significant role in EMT?.

S100A4 expression levels strongly correlate with motility, which is a central element of the metastatic cascade ${ }^{25}$. In oral squamous cell carcinoma (OSCC), metastasis results in $90 \%$ of cancer associated mortality. In this work, we studied the role of S100A4 in oral cancer as a biomarker of metastasis by assessing its expression in primary tumors from all the clinical stages of oral cancer and determined the association of S100A4 expression 
with aggressive clinico-pathological parameters including the pattern of invasion, distant metastasis and recurrence. Assessment of S100A4 in oral cancer may be related to the phenotypic alteration and thereby predict its metastatic potential.

\section{MATERIAL AND METHODS}

\section{Patient details}

The material for present study included a total of 57 formalin fixed paraffin embedded tissue sections retrieved from the departmental archives. Out of these, 47 were patients with carcinoma of the bucco-alveolar mucosal complex and of the floor of the mouth. The remaining 10 were healthy mucosal tissues, which were obtained at the time of extraction of impacted teeth. Only surgically treated cases of oral squamous cell carcinoma (OSCC) with a minimum follow-up period of 5 years were included in the study. Institutional Ethics Committee approval (IEC 36/2012) was obtained from Kasturba Hospital, Manipal, prior to carrying out the study. The patient demographics and other details of the cases included in the study are presented in Table 1 . A chart analysis was carried out to study the expression of S100A4 in all these cases by immunohistochemistry (IHC). Tissue sections obtained from the lymph node constituted the positive control.

\section{Immunohistochemistry}

Immunohistochemical staining was carried out using indirect streptavidin biotin immunoperoxidase technique. The antibodies and reagents were obtained from Sigma - Aldrich Co. (St. Louis, MO, USA). Sections of $4 \mu \mathrm{m}$ thickness taken on amino propyl triethoxysilane (APES) coated slides were incubated overnight at $48^{\circ} \mathrm{C}$ in a slide warmer to ensure complete adhesion of sections. Following tissue sections deparaffinization and hydration through descending grades of alcohol, sections were placed in phosphate buffered saline (PBS) for 30 minutes. The slides were immersed in a microwave resistant plastic staining jar containing antigen retrieval solution ( $10 \mathrm{mM}$ sodium citrate buffer, $\mathrm{pH}$ 6.0) and maintained at $700 \mathrm{~W}$ power for 10 minutes. Subsequently, the solution was allowed to cool at room temperature for at least 20 minutes. The slides were incubated in 3\% hydrogen peroxide for 5 minutes at room temperature, following which slides were washed with PBS. To decrease the background staining due to nonspecific binding of antibodies, the slides were incubated with $5 \%$ bovine serum albumin (BSA) for 10 minutes at room temperature and washed with PBS for 5 minutes. The researchers applied $100 \mu \mathrm{L}$ of the primary antibody (Rabbit polyclonal anti-S100A4 antibody, $1: 250)$ over the section completely, which was incubated for 60 minutes at $37^{\circ} \mathrm{C}$ in a humidified chamber. The slides were rinsed with PBS and placed in the PBS bath for 5 minutes. After draining and wiping of the slides, sections were incubated in $100 \mu \mathrm{l}$ of biotinylated secondary antibody, AntiRabbit IgG (whole molecule - Peroxidase antibody produced in goat) for 30 minutes at $37^{\circ} \mathrm{C}$. The slides were washed with PBS and placed in PBS bath for 5 minutes. For visualization, sections were incubated with freshly prepared substrate solution (SIGMAFAST $^{\mathrm{m}}$ 3, 3'-Diaminobenzidine tablets) for 5-10 minutes. This was followed by washing the slides in running tap water and counter staining with Mayer's haematoxylin (MHS1- Haematoxylin Solution, Mayer's $1 \mathrm{~g} / \mathrm{L}$ certified hematoxylin *pH 2.4) for 5 minutes, after which the slides were washed in running tap water for 1 minute. Briefly,

Table 1- The demographic variable of the cases included in the study

\begin{tabular}{|c|c|c|c|c|}
\hline Particulars & Subset & Number & $(\%)$ & Total \\
\hline \multirow[t]{2}{*}{ Gender } & Male & 37 & 78.72 & 47 \\
\hline & Female & 10 & 21.28 & \\
\hline \multirow[t]{3}{*}{ Site } & Buccal mucosa & 21 & 44.68 & 47 \\
\hline & Alveolus & 18 & 38.30 & \\
\hline & Floor of the mouth & 8 & 17.02 & \\
\hline \multirow[t]{4}{*}{ Presentation } & Ulceroproliferative & 26 & 55.32 & 47 \\
\hline & Ulcer & 8 & 17.02 & \\
\hline & Exophytic & 8 & 17.02 & \\
\hline & Swelling & 5 & 10.64 & \\
\hline \multirow[t]{4}{*}{ Habit } & SLT & 26 & 55.32 & 47 \\
\hline & ST & 12 & 25.53 & \\
\hline & $S L T+S T$ & 3 & 6.38 & \\
\hline & NT & 6 & 12.77 & \\
\hline
\end{tabular}

SLT - Smokeless tobacco. S - Smoking tobacco. NT- No tobacco 
the sections were dehydrated through ascending grades of alcohol (70\%, 95\% and $100 \%)$ for 2 minutes each, cleared in xylene for 1 minute, mounted in a resinous media and coverslipped.

\section{Staining interpretation}

The neoplastic cell with cytoplasmic staining was viewed at $200 \times$ magnification, using a light microscope. The distribution of immunolabelling in neoplastic epithelial cells was determined from a minimum of five representative high-power fields at the invasive front. A positive cell demonstrated a diffuse brown signal in the cytoplasm, independent of its intensity. To eliminate any inter-observer bias, the scoring was carried out independently by two observers. The degree of staining for S100A4 was evaluated using a semi-quantitative scale ${ }^{29}$. Tissues were graded as absent (-) when there was

Table 2-Association of S100A4 expression with clinical stage, lymph node involvement, tumor size, metastasis, recurrence, grade of tumor and pattern of invasion

\begin{tabular}{|c|c|c|c|c|c|c|}
\hline Parameters & 0 & $2+$ & $3+$ & Total & Chi-square & $p$ value \\
\hline \multicolumn{7}{|l|}{ Stage } \\
\hline Stage I & 5 & 1 & 0 & 6 & & \\
\hline Stage II & 1 & 1 & 0 & 2 & & \\
\hline Stage III & 4 & 5 & 8 & 17 & 14.5 & 0.007 \\
\hline Stage IV & 7 & 1 & 14 & 22 & & \\
\hline Total & 17 & 8 & 22 & 47 & & \\
\hline \multicolumn{7}{|l|}{ Lymphnode } \\
\hline No & 8 & 0 & 2 & 10 & & \\
\hline Yes & 3 & 6 & 20 & 29 & 22.7 & $<0.001$ \\
\hline Total & 11 & 6 & 22 & 39 & & \\
\hline \multicolumn{7}{|l|}{ Tumor Size } \\
\hline $\mathrm{T} 1$ & 5 & 2 & 4 & 11 & & \\
\hline $\mathrm{T} 2$ & 2 & 5 & 7 & 14 & & \\
\hline T3 & 3 & 0 & 1 & 4 & 8.7 & 0.15 \\
\hline $\mathrm{T} 4$ & 7 & 1 & 10 & 18 & & \\
\hline Total & 17 & 8 & 22 & 47 & & \\
\hline \multicolumn{7}{|l|}{ Metastasis } \\
\hline No & 7 & 0 & 4 & 11 & & \\
\hline Yes & 0 & 1 & 10 & 11 & 10.71 & 0.004 \\
\hline Total & 7 & 1 & 14 & 22 & & \\
\hline \multicolumn{7}{|l|}{ Recurrence } \\
\hline No & 11 & 6 & 11 & 28 & & \\
\hline Yes & 0 & 0 & 11 & 11 & 11.4 & 0.002 \\
\hline Total & 11 & 6 & 22 & 39 & & \\
\hline \multicolumn{7}{|l|}{ Grade } \\
\hline WDSCC & 6 & 4 & 5 & 15 & & \\
\hline MDSCC & 8 & 4 & 9 & 21 & 5.07 & 0.27 \\
\hline PDSCC & 3 & 0 & 8 & 11 & & \\
\hline Total & 17 & 8 & 22 & 47 & & \\
\hline \multicolumn{7}{|l|}{$\begin{array}{l}\text { Pattern of } \\
\text { invasion }\end{array}$} \\
\hline Type 1 & 2 & 1 & 1 & 4 & & \\
\hline Type 2 & 6 & 2 & 0 & 8 & & \\
\hline Type 3 & 6 & 3 & 2 & 11 & 27.4 & $<0.001$ \\
\hline Type 4C & 3 & 2 & 7 & 12 & & \\
\hline Type 4D & 0 & 0 & 12 & 12 & & \\
\hline Total & 17 & 8 & 22 & 47 & & \\
\hline
\end{tabular}

WDSCC - Well differentiated squamous cell carcinoma; MDSCC - Moderately differentiated squamous cell carcinoma; PDSCC - Poorly differentiated squamous cell carcinoma 
no staining, low $(1+)$ when less than $25 \%$ of the tumor cells were positive, moderate $(2+)$ when 25 to $75 \%$ of the tumor cells stained positively and diffuse $(3+)$ when more than $75 \%$ of the tumor cells were positive for S100A4. S100A4 expression was then correlated with clinicopathological parameters including primary tumor site, stage of tumor, degree of differentiation, lymph node metastasis and mode (pattern) of invasion 28 .

\section{Statistics}

Statistical analysis was carried out using SPSS version 16.0 for Windows. Kendall's tau-b statistics was applied to assess the measure of agreement between two observers. Chi-square test was used to study the association between the S100A4 staining and clinicopathological parameters. Results were considered statistically significant if $p<0.05$.

\section{RESULTS}

Positive S100A4 expression in the cytoplasm of the tumor cells was observed in 30 out of 47 cases $(63.82 \%)$ of OSCC. Kendall's tau-b test between the two observers showed a very high level of agreement for the expression of S100A4 (0.8, $\mathrm{p}<0.001)$. In the control group, none of oral mucosal tissues were positive for S100A4 in the cytoplasm of the epithelium.

Out of 47 cases studied, $1 / 6$ of stage I, $1 / 2$ of stage II, $13 / 17$ of stage III and $15 / 22$ of stage IV cases showed positive S100A4 expression (Table 2). A strong association was noted between the stage of the tumor and the expression score of S100A4 $(p=0.007) . S 100 A 4$ expression was positive in $12 / 14$ $(85.7 \%)$ node positive stage III cases, of which $7 / 12$ were $(3+)$ and $5 / 12$ were $(2+)$ for S100A4 expression. Among the node negative cases, $1 / 3$ cases showed (3+) for S100A4 expression. Likewise, S100A4 expression was positive in 14/15 (93.3\%) stage IV cases, of which $13 / 14$ were $(3+)$ and $1 / 14$ was $(2+)$. Among the 7 node negative cases, $1 / 7$ was $(3+)$ and the remaining $6 / 7$ cases were negative for S100A4 expression. Although the cytoplasmic expression of S100A4 was strongly associated with lymph node involvement $(p<0.001)$, there was no association between S100A4 expression in lymph node positive cases and primary size of the tumor $(p=0.15)$.

With regard to distant metastasis (M), 11/22 $(50 \%)$ cases in stage IV were positive for S100A4 expression, out of which $10 / 11$ were $(3+)$ and $1 / 11$ was $(2+)$ for S100A4 expression. A strong association could be established between the S100A4 expression in tumor cells and distant metastasis $(p=0.004)$. Likewise, $11 / 47$ (23.4\%) cases that recurred after treatment were either in stage III (2/11) or stage IV (9/11). All these cases showed $(3+)$ expression for S100A4. Among the stage III cases that recurred, one was node positive and the other was negative, whereas all the 9 stage IV cases that recurred were node positive. There was a strong positive association between the S100A4 expression and rate of recurrence $(p=0.002)$.

With regard to the pattern of invasion among the positive cases, $1 / 6$ cases of stage I showed a type 1 (Figure 1 ) pattern and $1 / 2$ cases in stage II showed type 2 (Figure 2) pattern. Out of the 13 stage III cases that showed positive S100A4 expression, 2 were type 1, 2 others were type 2, 3 were type 3 (Figure 3), 3 were type 4C (Figure 4 ) and 3 were type 4D (Figure 5). In the same manner, out of the 15 stage IV cases that showed positive S100A4 expression, 2 were type 3, 4 were type $4 \mathrm{C}$ and 9 were type 4D. There was a strong association $(p<0.001)$ between S100A4 expression and pattern of invasion of OSCC. However, there was no association seen between the S100A4 expression and histological grade of the OSCC $(p=0.27)$.

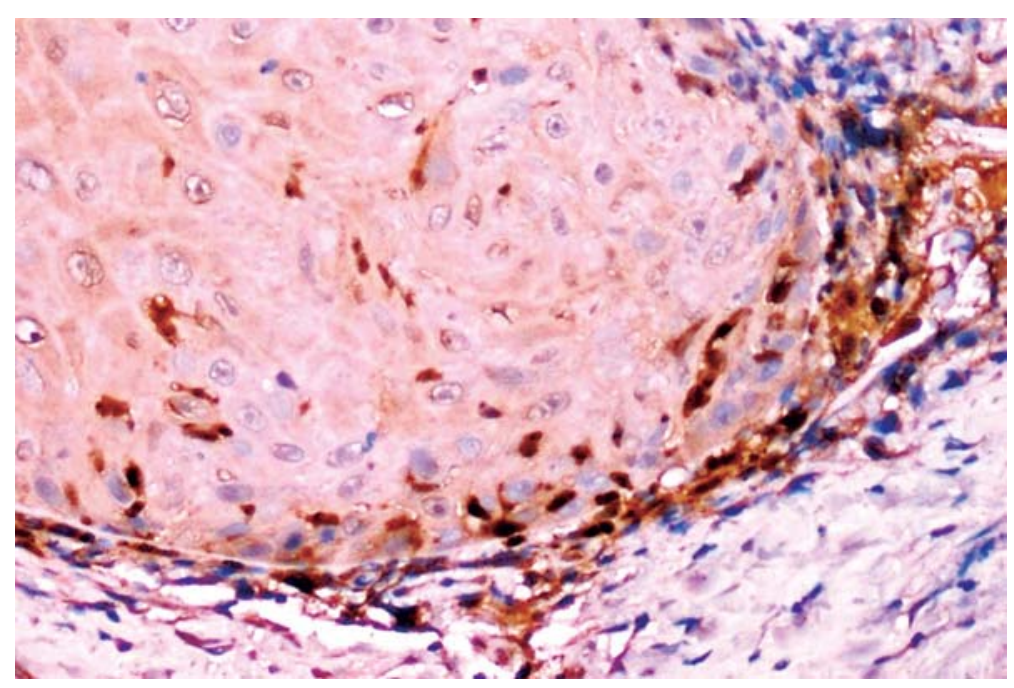

Figure 1- Oral squamous cell carcinoma (OSCC) showing type 1 well defined borderline pattern of invasion (S100A4, 20x) 


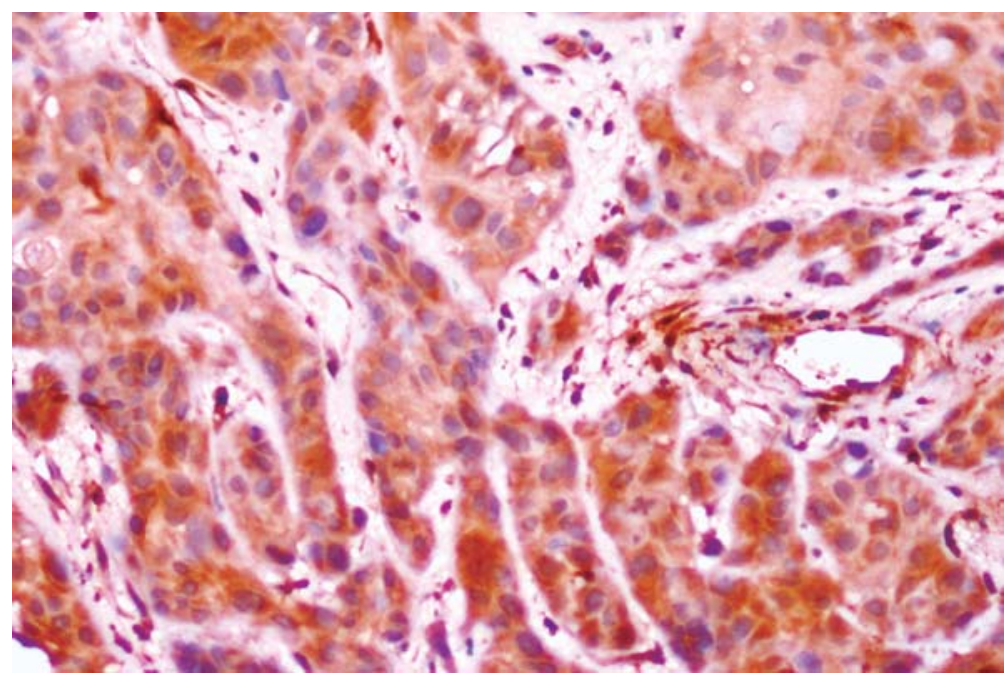

Figure 2- Oral squamous cell carcinoma (OSCC) showing type 2 cord like pattern of invasion (S100 A4, 20x)

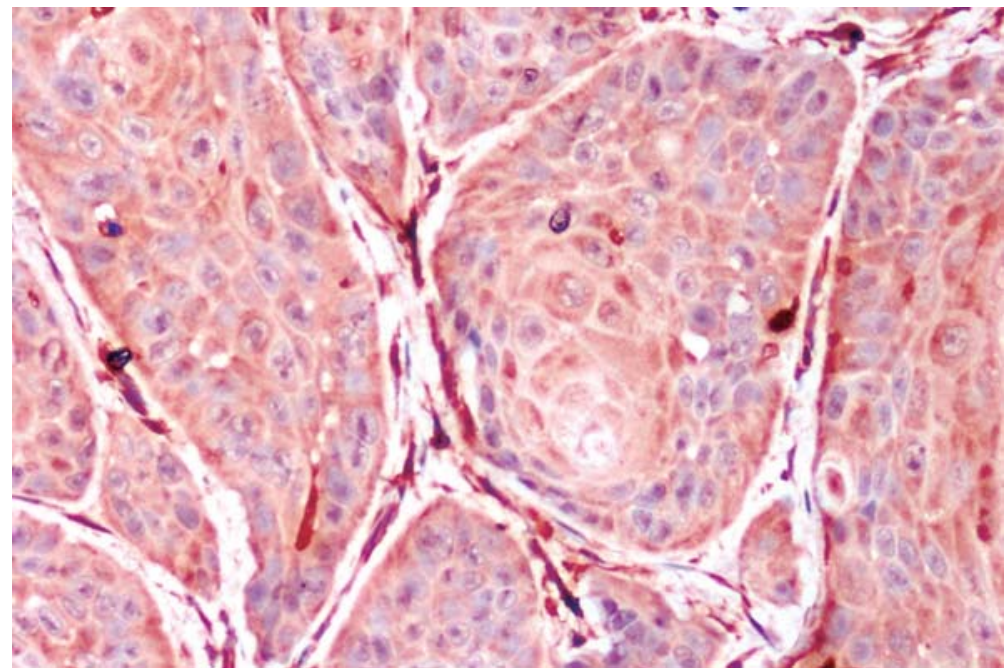

Figure 3- Oral squamous cell carcinoma (OSCC) showing type 3 pattern of invasion with groups of cells with no distinct borderline (S100A4, 20x)

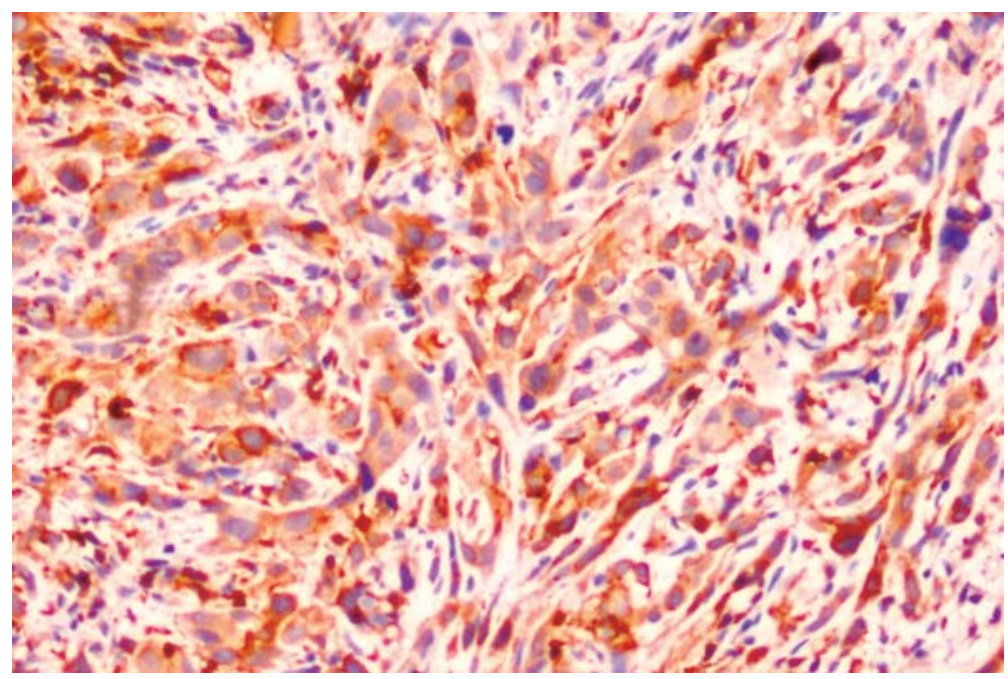

Figure 4- Oral squamous cell carcinoma (OSCC) showing type 4C diffuse cord like pattern of invasion (S100A4, 20x) 


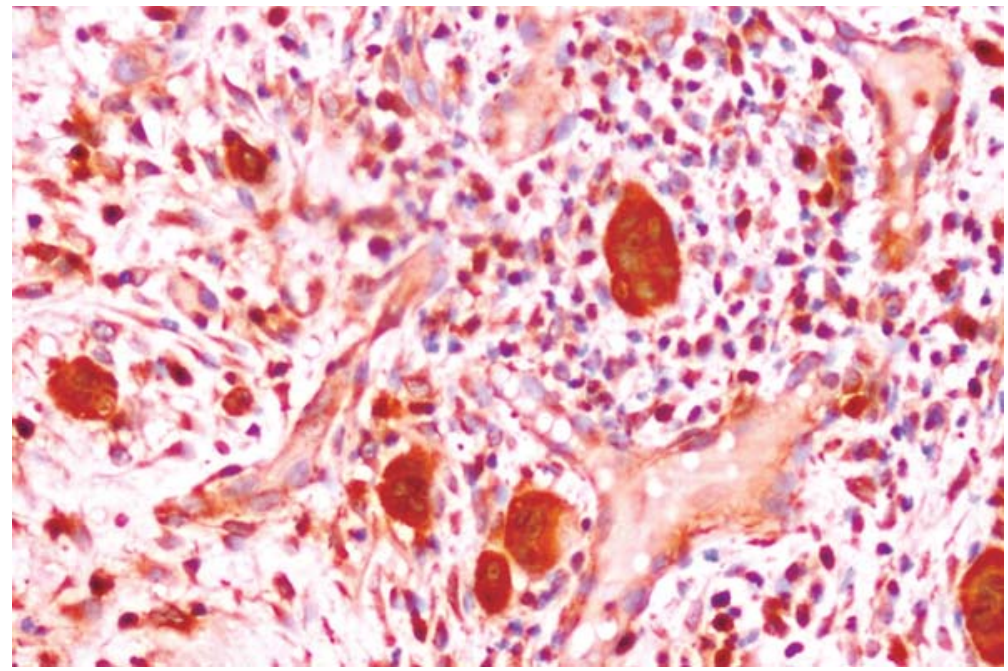

Figure 5- Oral squamous cell carcinoma (OSCC) showing type 4D diffuse widespread pattern of invasion (S100A4, 20x)

\section{DISCUSSION}

Oral cancer is one of the major cancers worldwide, with a low five-year survival rate that has not significantly changed over the past few decades $^{12}$. Metastasis, which is responsible for $90 \%$ of the cancer associated mortality, is one of the poorly understood factors in cancer progression. An important step for the invasion and metastasis is the epithelial mesenchymal transition (EMT), a complex process induced by modifications of multiple pathways leading to a spectrum of epithelial cellular changes, including loss of polarity and cohesion, increased motility, and the acquisition of mesenchymal phenotype. EMT is critical for the invasion, progression, and metastasis in epithelial carcinogenesis $^{8}$. Understanding the modulators of EMT may provide information of specific molecular targets.

Metastasis promoting S100A4 is a typical representative of $\mathrm{S} 100$ family of $\mathrm{Ca} 2+$-binding multifunctional proteins with dual extra- and intracellular function ${ }^{5}$. The increased expression of the S100A4 in invasive front of the tumor suggests the pivotal role played by S100A4 in invasion of tumor cells into the surrounding matrix. The acquisition of invasive phenotype with altered pattern of adhesion is a result of E-cadherin down regulation by $\mathrm{S} 100 \mathrm{~A} 4$, which the tumor cells acquire $^{14}$. S100A4 further influences cell-matrix adhesions by interacting with liprin $\beta 1$ and masking their protein kinase $\mathrm{C}$-mediated phosphorylation sites $^{17}$. Inhibition of the liprin $\beta 1$-LAR complex by S100A4 loosens cell adhesion and allows cell invasion. Cell invasion is also facilitated by matrix metalloproteinases (MMPs), as S100A4 causes metastasis not only by affecting the motility of cells but also by affecting its invasive properties through influencing the expression of MMPs and their endogenous inhibitors ${ }^{2}$. A positive correlation of the S100A4 and MMP2 expression in oesophageal squamous cell carcinoma has been reported ${ }^{29}$.

S100A4 is located at the leading edge of migrating cells ${ }^{15}$, where it induces the formation of flexible protrusions. Moreover, in the presence of a chemoattractant, S100A4 enhances directed migration. Directed migration is dependent on the interaction of S100A4 with myosin II-A. Thus, the S100A4-myosin II-A interaction does not only increase cell motility, but also enhances cell polarization and directed migration ${ }^{19}$. S100A4 also binds to the septins 2, 6 and 7, which play a central role in cytokinesis, cell polarity determination, cytoskeletal reorganization, and membrane dynamics ${ }^{10,16}$. Therefore, the S100A4septin interaction also contributes to the process of migration.

S100A4 protein contributes to tumor angiogenesis by stimulating the motility of endothelial cells. S100A4 binds to annexin II on the endothelial surface, a complex that activates the tissue plasminogen activator, which in turn converts the plasminogen to plasmin, activating proMMPs. Active MMPs and plasmin together induce extracellular matrix remodelling and thereby facilitate angiogenesis ${ }^{26}$. Intracellular S100A4 also enhances angiogenesis by interacting with methionine aminopeptidase 2 (MetAP2) $^{6}$. $\mathrm{Ca}^{2+}$-dependent binding of S100A4 to MetAP2 modulates the MetAP2 activity, which could promote endothelial growth and angiogenesis. This process of angiogenesis favors the metastasis of the tumor to the regional lymph nodes.

Elevated S100A4 expression has shown to be the marker of metastasis and poor prognosis in patients with pancreatic ductal adenocarcinoma ${ }^{23}$, prostate adenocarcinoma ${ }^{9}$, colorectal cancer ${ }^{4,18}$ and breast cancer ${ }^{24}$. A higher level of S100A4 expression has shown to correlate with auxillary lymph node metastasis and overall patient survival ${ }^{24}$. 
Evidence suggesting the role for S100A4 in HNSCC, especially in OSCC, is scarce. Elevated S100A4 as a prognostic factor in metastatic cases of OSCC was demonstrated by Moriyama-Kita, et al. ${ }^{21}$ (2004). Our findings showing increased expression of S100A4 in cases with regional lymphnode involvement and metastasis further emphasizes the role of S100A4 in oral cancer patients with poor prognosis.

The final step in the metastatic cascade is the migration of the cells to a distant site and secondary colonization. In our study we found a significant correlation with the elevated S100A4 expression and distant metastasis. This finding has been elucidated earlier in papillary thyroid carcinoma ${ }^{30}$ and pancreatic cancer ${ }^{22}$, in which poor outcome of patients was related to increased S100A4 expression coupled with decreased E cadherin expression.

The increased expression of S100A4 in our study showed a significant correlation with the overall clinical stage of tumor, a finding that has been noted also in colorectal carcinoma ${ }^{4}$ and pancreatic cancer ${ }^{22}$. However, no association could be drawn between the elevated S100A4 level and the primary tumor size or histological grading in our analysis. These findings are in agreement with MoriyamaKita, et al. ${ }^{21}$ (2004) in OSCC and Chen, et al. ${ }^{3}$ (2014) in lung cancer cells, in which S100A4 was frequently overexpressed, irrespective of histological subtype.

In our study a strong association between S100A4 expression and pattern of invasion could be elicited, with an increased expression noted in type 4C and type 4D pattern of invasion. Similar observations have been made in malignant melanomas where increased expression of S100A4 in the nodular variant was noted, linking this association to the pattern of invasion ${ }^{1}$.

Significantly, our observation of high S100A4 expression with tumor recurrence is a novel finding. S100A4 has been identified as a candidate marker for maintaining the stemness in head and neck cancer initiating cells. S100A4 controls the Notch and PTEN/PI3K/Akt signaling pathways, which regulate the self-renewal and tumorigenicity of stem cells or cancer stem cells ${ }^{20}$. S100A4 signaling pathways thus play a major role in the maintenance of cancer initiating cell population and contribute for the tumor recurrence.

\section{CONCLUSION}

In summary, the data from our study adds weight to the growing body of evidence that S100A4 can be used to identify the subgroup of patients at high risk of metastasis and recurrence in OSCC cases, and that targeting S100A4 signaling might be a potential therapeutic target for increasing the patient survival.

\section{REFERENCES}

1- Andersen K, Nesland JM, Holm R, Flørenes VA, Fodstad $\varnothing$, Maelandsmo GM. Expression of S100A4 combined with reduced E-cadherin expression predicts patient outcome in malignant melanoma. Mod Pathol. 2004;17:990-7.

2- Bjornland K, Winberg JO, Odegaard OT, Hovig E, Loennechen T, Aasen AO, et al. S100A4 involvement in metastasis: deregulation of matrix metalloproteinases and tissue inhibitors of matrix metalloproteinases in osteosarcoma cells transfected with an anti-S100A4 ribozyme. Cancer Res. 1999;59:4702-8.

3- Chen N, Sato D, Saiki Y, Sunamura M, Fukushige S, Horii A. S100A4 is frequently overexpressed in lung cancer cells and promotes cell growth and cell motility. Biochem Biophys Res Commun. 2014;447:459-64.

4- Cho YG, Kim CJ, Nam SW, Yoon SH, Lee SH, Yoo NJ, et al. Overexpression of S100A4 is closely associated with progression of colorectal cancer. World J Gastroenterol. 2005;11:4852-6.

5 - Donato R. Intracellular and extracellular roles of S100 proteins. Microsc Res Tech. 2003;60:540-51.

6- Endo H, Takenaga K, Kanno T, Satoh H, Mori S. Methionine aminopeptidase 2 is a new target for the metastasis-associated protein, S100A4. J Biol Chem. 2002;277:26396-402.

7- Garrett SC, Varney KM, Weber DJ, Bresnick AR. S100A4, a mediator of metastasis. J Biol Chem. 2006;281:677-80.

8- Gupta GP, Massagué J. Cancer metastasis: building a framework. Cell. 2006;127:679-95.

9- Gupta S, Hussain T, MacLennan GT, Fu P, Patel J, Mukhtar H. Differential expression of S100A2 and S100A4 during progression of human prostate adenocarcinoma. J Clin Oncol. 2003;21:106-12. 10- Hall PA, Russell SE. The pathobiology of the septin gene family. J Pathol. 2004;204:489-505.

11- Hanahan D, Weinberg RA. The hallmarks of cancer. Cell. 2000;100:57-70.

12- Jemal A, Thomas A, Murray T, Thun M. Cancer statistics, 2002. CA Cancer J Clin. 2002;52:23-47.

13- Kalluri R, Weinberg RA. The basics of epithelial-mesenchymal transition. J Clin Invest. 2009;119:1420-8.

14- Keirsebilck A, Bonné S, Bruyneel E, Vermassen P, Lukanidin E, Mareel M, et al. E-cadherin and metastasin (mts-1/S100A4) expression levels are inversely regulated in two tumor cell families. Cancer Res. 1998;58:4587-91.

15- Kim EJ, Helfman DM. Characterization of the metastasisassociated protein, S100A4. Roles of calcium binding and dimerization in cellular localization and interaction with myosin. J Biol Chem. 2003;278:30063-73.

16- Koshelev YA, Kiselev SL, Georgiev GP. Interaction of the S100A4 (Mts1) protein with septins Sept2, Sept6, and Sept7 in vitro. Dokl Biochem Biophys. 2003;391:195-7.

17- Kriajevska M, Fischer-Larsen M, Moertz E, Vorm O, Tulchinsky E, Grigorian M, et al. Liprin beta 1, a member of the family of LAR transmembrane tyrosine phosphatase-interacting proteins, is a new target for the metastasis-associated protein S100A4 (Mts1). J Biol Chem. 2002;277:5229-35.

18- Kwak JM, Lee HJ, Kim SH, Kim HK, Mok YJ, Park YT, et al. Expression of protein S100A4 is a predictor of recurrence in colorectal cancer. World J Gastroenterol. 2010;16:3897-904.

19- Li ZH, Spektor A, Varlamova O, Bresnick AR. Mts1 regulates the assembly of nonmuscle myosin-IIA. Biochemistry. 2003;42:14258-66.

20- Lo JF, Yu CC, Chiou SH, Huang CY, Jan CI, Lin SC, et al. The epithelial-mesenchymal transition mediator S100A4 maintains cancer-initiating cells in head and neck cancers. Cancer Res. 2011;71:1912-23.

21- Moriyama-Kita M, Endo Y, Yonemura Y, Heizmann CW, Schäfer BW, Sasaki T, et al. Correlation of S100A4 expression with invasion and metastasis in oral squamous cell carcinoma. Oral Oncol. 2004;40:496-500. 
22- Oida Y, Yamazaki H, Tobita K, Mukai M, Ohtani Y, Miyazaki $\mathrm{N}$, et al. Increased S100A4 expression combined with decreased $\mathrm{E}$-cadherin expression predicts a poor outcome of patients with pancreatic cancer. Oncol Rep. 2006;16:457-63.

23- Rosty C, Ueki T, Argani P, Jansen M, Yeo CJ, Cameron JL, et al. Overexpression of S100A4 in pancreatic ductal adenocarcinomas is associated with poor differentiation and DNA hypomethylation. Am J Pathol. 2002;160:45-50.

24- Rudland PS, Platt-Higgins A, Renshaw C, West CR, Winstanley $\mathrm{JH}$, Robertson L, et al. Prognostic significance of the metastasisinducing protein S100A4 (p9Ka) in human breast cancer. Cancer Res. 2000;60:1595-603.

25- Santamaria-Kisiel L, Rintala-Dempsey AC, Shaw GS. Calciumdependent and -independent interactions of the S100 protein family. Biochem J. 2006;396:201-14.

26- Semov A, Moreno MJ, Onichtchenko A, Abulrob A, Ball M, Ekiel I, et al. Metastasis-associated protein S100A4 induces angiogenesis through interaction with Annexin II and accelerated plasmin formation. J Biol Chem. 2005;280:20833-41.
27- Smit MA, Peeper DS. Epithelial-mesenchymal transition and senescence: two cancer-related processes are crossing paths. Aging (Albany NY). 2010;2:735-41.

28- Yamamoto E, Miyakawa A, Kohama G. Mode of invasion and lymph node metastasis in squamous cell carcinoma of the oral cavity. Head Neck Surg. 1984;6:938-47.

29- Zhang HY, Zheng XZ, Wang XH, Xuan XY, Wang F, Li SS. S100A4 mediated cell invasion and metastasis of esophageal squamous cell carcinoma via the regulation of MMP-2 and E-cadherin activity. Mol Biol Rep. 2012;39:199-208.

30- Zou M, Al-Baradie RS, Al-Hindi H, Farid NR, Shi Y. S100A4 (Mts1) gene overexpression is associated with invasion and metastasis of papillary thyroid carcinoma. $\mathrm{Br} \mathrm{J}$ Cancer. 2005;93:1277-84. 